\title{
Do Conceito à Prática da Autonomia do Professor de Matemática
}

\author{
From Concept to Practice of Autonomy of Mathematics Teacher
}

\author{
Antonio Carlos Carrera de Souza \\ Michela Tuchapesk da Silva**
}

\begin{abstract}
Resumo
O texto apresenta articulações teóricas e práticas de uma pesquisa de doutorado concluída que pretendeu fomentar discussões acerca das possibilidades do professor de Matemática no que se refere a 'autonomia', ao 'cuidado de si' segundo Michel Foucault (2010). Apropriando-se do método da cartografia - mapeamento da subjetividade humana - realizou-se, durante o período de um ano, encontros semanais, com os professores de Matemática de uma escola pública do interior do Estado de São Paulo possibilitando uma intervenção que buscou mapear as linhas de forças que circulavam neste espaço de diálogo e, consequentemente, discutir seus processos de subjetivação. Assim, acreditamos na possibilidade dos conceitos aqui apresentado produzirem novas formas de visibilidades na escola, gerando a possibilidade de constituir novos modos de existência, possíveis espaços de liberdade no presente.
\end{abstract}

Palavras-chave: Filosofia da Diferença. Cuidado de si. Processos de subjetivação. Educação Matemática.

\begin{abstract}
This paper presents theoretical and practical articulations of a concluded doctoral research. Our goal is to promote discussions about mathematics teachers possibilities related to the 'autonomy', the 'self care' according to Michel Foucault (2010). During the period of one year appropriating the method of cartography - mapping the human subjectivity - by weekly meetings with mathematics teachers of a public school in São Paulo state countryside, an intervention was made possible, which intends to map the force lines that circulated in this space of dialogue and, therefore, to discuss theirs process of subjectivation. Thus, we believe in the possibility of the concepts presented here producing new forms of visibilities at school, creating the possibility of establishing new ways of existence and possible spaces of freedom in the present.
\end{abstract}

Keywords: Philosophy of Difference. Self-Care. Proceedings of Subjectivity. Mathematic Education.

\section{Encontros no território escola}

\footnotetext{
* Livre-Docente em Educação Matemática pela Universidade Estadual Paulista (UNESP), Rio Claro/SP; Doutor em Educação pela Universidade Estadual de Campinas (UNICAMP), Campinas/SP; Professor Aposentado da Universidade Estadual Paulista (UNESP), Rio Claro/SP e Voluntário do Programa de Pós Graduação em Educação Matemática da Universidade Estadual Paulista (UNESP), Rio Claro/SP. Endereço para correspondência: Avenida 1-A, 899, Cidade Nova, Rio Claro/SP, CEP 13506-785. E-mail: accs62@gmail.com. ** Doutora em Educação Matemática pela Universidade Estadual Paulista (UNESP), Rio Claro/SP. Endereço para correspondência: Rua Ray Wesley Herrick, 1501, casa 33, Jockey Club, São Carlos/SP, CEP: 13565-090. E-mail: mtucha@yahoo.com.br.
} 
Apresentamos aqui agenciamentos teóricos e práticos de uma pesquisa de doutorado já concluída ${ }^{1}$, que desenvolveu sua produção de dados durante o ano letivo de 2011 numa escola pública do interior do Estado de São Paulo realizando encontros semanais com os professores de Matemática. Estes encontros buscaram constituir a prática do exercício de olhar para si mesmo, conhecer a si mesmo, cuidar de si, se governar (FOUCAULT, 2010). Neste percurso identificamos processos de subjetivações, exercitando a visão háptica, mais do que óptica. Acompanhando processos com olhares outros, imergimos nos planos das intensidades e atiramo-nos ao aprendizado dos afetos. Assim, realizamos uma produção de conhecimento com, entre, em movimento, buscando, nesta prática, a possibilidade da escola real se atualizar na escola virtual.

Amparados em Deleuze (2005), Foucault (2009) e Rolnik (1989), em consonância com o pensamento da Filosofia da Diferença, nos apropriamos do método da cartografia na realização da produção de dados $^{2}$ desse trabalho de pesquisa. Ressaltando que a semântica da palavra cartografia, aqui, se refere à cartografia da subjetividade humana

[...] onde o mapa construído não é um mapa físico que estabelece limites de acordo com as fronteiras de um mapa-múndi, nem visa mapear processos e procedimentos de professores de matemática e outros sujeitos da escola, mas sim um mapa das subjetivações humanas de acordo com Michel Foucault [...] (SILVA et al, 2013, p. 2).

A cartografia, assim, propõe uma topografia das forças do fora, uma geografia das afetações. Portanto, cartografia como impulso de trazer algo novo para o mundo, que nos movimente, que ative um pensamento, uma escola. Neste sentido, a escola é entendida como um território das afetações e subjetivações. No território escola surge o dispositivo ATPC de Matemática ${ }^{3}$, território das conversas semanais entre a pesquisadora e os professores de Matemática. Possibilidade de envolvimentos, movimentos, experiências, sensações, desterritorializações, agenciamentos entre a pesquisadora, professores e a escola. Uma intervenção que pretendeu provocar as linhas de forças que circulavam neste espaço de

\footnotetext{
${ }^{1}$ SILVA, M.T. A Educação Matemática e o cuidado de si: possibilidades foucaultianas. 2014. 192f. Tese (Doutorado) - Curso de Educação Matemática. UNESP, Rio Claro, 2014.

2 Apoiados em Kastrup e Escóssia (2009), destacamos que o termo produção de dados reporta à ideia de que, nesta pesquisa, os dados não são coletados, mas sim produzidos desde a etapa inicial da pesquisa de campo até as etapas posteriores, abrangendo a escrita de textos e ainda a contribuição dos participantes desse estudo na produção coletiva do conhecimento.

${ }^{3}$ A sigla ATPC - Aula de Trabalho Pedagógico Coletivo a partir do ano de 2012 substituiu a sigla HTPC - Hora de Trabalho Pedagógico Coletivo, porém manteve a mesma função. A HTPC foi instituída nas escolas públicas pelo Governo do Estado de São Paulo através da portaria CENP n 1/96, lei complementar n836/1997, artigo 13. A escola pesquisada cedeu uma hora da ATPC para a realização dos encontros da pesquisadora com os professores. Portanto, ATPC de Matemática foi o título atribuído pela escola a esses encontros semanais da pesquisadora com os professores de Matemática que aceitaram participar da pesquisa.
} 
diálogo, conversa entre os professores e a pesquisadora. Encontro semanal com os professores de Matemática: um dispositivo como potência de movimentos e fluxos de pensares outros.

O dispositivo é a rede de relações que podem ser estabelecidas entre elementos heterogêneos: discursos, instituições, arquitetura, regramentos, leis, medidas administrativas, enunciados científicos, proposições filosóficas, morais, filantrópicas, o dito e o não dito (CASTRO, 2009, p. 124).

Os encontros e as conversas entre os professores de Matemática e a pesquisadora, se desenvolveram no sentido atribuído por Deleuze e Parnet (1998).

Encontram-se pessoas [...] mas também movimentos, ideias, acontecimentos,
entidades. [...]. Encontrar é achar, é capturar, é roubar, mas não há método para
achar, nada além de uma longa preparação. Roubar é o contrário de plagiar, de
copiar, de imitar ou de fazer como. A captura é sempre uma dupla-captura, o roubo,
um duplo-roubo, e é isso que faz, não algo de mútuo, mas um bloco assimétrico,
uma evolução a-paralela, núpcias, sempre "fora" e "entre". Seria isso, pois, uma
conversa (DELEUZE; PARNET, 1998, p. 6-7).

Do ponto de vista metodológico as pesquisas em cartografia utilizam toda a vasta gama de encontros possíveis das reuniões de ATPC com os professores até os mapas narrativos $^{4}$. Neste artigo buscamos ressonâncias teóricas nas narrativas concretas dos professores da escola pesquisada em Silva (2014). Assim, ressaltamos que o artigo pretende manter o formato da tese (SILVA, 2014), em que as falas dos sujeitos de pesquisa apresentam ressonâncias com o texto. Por isto mantivemos a fala dos professores de Matemática de forma distinta do corpo teórico do texto, provocando aí a intertextualidade box/texto que o leitor, a seu juízo, fará. Entendemos que desta forma os boxes não interrompem o texto e sim provocam a ressonância teórica do mesmo. Neste primeiro box, por exemplo, mostramos as ressonâncias das práticas utilizadas na ATPC, durante a pesquisa, na narrativa dos professores.

Pati: Eu pensei que você fosse expor na ATPC de Matemática sua pesquisa de mestrado, doutorado. Mas nesses encontros a gente conversava sobre o que acontecia aqui, a gente falava o que acontecia na sala de aula. E se a gente não falava, a gente pensava.

Cris: Pela primeira vez eu tive a liberdade de contar sobre meus problemas na sala de aula de Matemática. Tive a possibilidade de pensar em mim!

Éder: Nessas ATPCs de Matemática só eu falava. Só eu falava! Eu falei, falei, falei. E a Cris só lamentava das mesmas coisas, exatamente os mesmos problemas em toda ATPC. Ela nunca falava assim: "Olha, eu fiz isso e deu certo!" Eu também tive problemas, mas eu tentei aplicar algumas coisas que conversávamos aqui e eu acho que eu tive sucesso. Eu até falava para os outros professores: "Agora eu vou para o muro das lamentações da Cris". Ela sempre reclamava das mesmas coisas: "Ah, porque o sétimo ano C...."

James: É, foi interessante, porque conversávamos sobre coisas da escola. Sabe? E "brotavam" ideias nessas conversas que acabavam refletindo na sala de aula. Mas não havia exigências tipo: "Precisamos fazer alguma coisa para melhorar a sala de aula de Matemática". Para cada professor

\footnotetext{
4 “[...] consistem em desenhos feitos pelos pesquisados a partir de temas propostos pelo pesquisador. Tais desenhos são acompanhados de narrativas dos pesquisados - que podem ser apontadas, gravadas e/ou filmadas pelo pesquisador - relativas não só ao desenho, mas de tudo que estes entenderem como necessário para contextualizar e dar sentido ao que está sendo desenhado" (SILVA et al, 2013, p. 2).
} 
a conversa "batia" de um jeito (Conversa da pesquisadora com os professores na ATPC de Matemática. SILVA, 2014, p.15).

ATPC de Matemática ${ }^{5}$

Esses encontros surgiram como possibilidade de o professor pensar as suas próprias subjetivações. Entendemos a ATPC de Matemática como uma dobra do fora que busca discutir os processos de subjetivação dos professores a fim de instruí-los a pensar sobre essas forças, identificar essas linhas, redes de saber e poder. Um exercício de olhar para questões outras, exercício de identificar as linhas do fora e entender o que deve subjetivá-los ou não. Encontros na ATPC de Matemática, possibilidade de criar mundos que fizessem os professores pensar nos seus mundos. “[...] É, a cada vez, inventar o entrelaçamento, lançar uma flecha de um contra o alvo do outro, fazer brilhar um clarão de luz nas palavras, fazer ouvir um grito nas coisas visíveis” (DELEUZE, 2005, p. 124).

Daí a importância de travarmos estudo com Michel Foucault, uma vez que a subjetividade foucaultiana analisa os processos que levam o sujeito a determinados tipos de lutas e subjetivações. Ressaltando que nossas subjetividades são construídas a partir das práticas que estamos colocados, consideramos de extrema relevância nos questionar: Queremos ficar subjetivados ao poder ou a nós mesmos? Para Foucault o sujeito deve ser subjetivado somente a ele mesmo.

[...] A luta por uma subjetividade moderna passa por uma resistência às duas formas atuais de sujeição, uma que consiste em nos individualizar de acordo com as exigências do poder, outra que consiste em ligar cada indivíduo a uma identidade sabida e conhecida, bem determinada de uma vez por todas. A luta pela subjetividade se apresenta então como direito à diferença e direito à variação, à metamorfose (DELEUZE, 2005, p. 113).

O trabalho de pesquisa percorreu essas linhas mínimas de frágeis constituições e colocou em prática movimentos transversais contrários aos movimentos verticais e horizontais existentes na escola visando fomentar discussões acerca das possibilidades do professor de Matemática no que se refere à autonomia, ao cuidado de si segundo Michel Foucault (2005, 2006, 2007, 2010).

\section{Mas, como se dá essa autonomia?}

O sujeito autônomo é aquele que sabe reconhecer as forças do fora e escolher aquela que ele deseja que o afete, que o atravesse, que o subjetive. Ou seja, o sujeito só é subjetivado pelas forças que ele deseja, que ele escolhe. Construída nas práticas de subjetivação essa

\footnotetext{
${ }^{5}$ Conversa da pesquisadora com os professores na ATPC de Matemática. Compilada de Silva (2014).
} 
autonomia de que falamos se trata de uma luta interna, constante, diária. O sujeito autônomo é aquele que se controla em todos os aspectos, ele se cuida integralmente, se autogoverna. A autonomia está dentro do sujeito, ela age como o controle do fora, controle das questões: Quais forças/subjetivações aceito? Quais rejeito? Portanto, pessoas autônomas vão resistir o tempo todo!

O sujeito é constituído por subjetivações. Contudo, o sujeito autônomo, livre, só aceita as forças que ele deseja, que ele aceita. Assim, as subjetivações são auto afetações que ele deixa passar, as que ele não deixa ele verga, rejeita. Deleuze (2005) chama isso de dobra, o sujeito tem uma dobra quando tem a possibilidade de resistir, quando tem a possibilidade de vergar forças que não o interessam (essas forças continuam no fora, no mundo das forças) e as que ele deixa passar constituirão as pregas ou as auto afetações. A autonomia que estudamos é algo conquistado pelo domínio dos desejos e prazeres do sujeito, ela não é algo dado. O sujeito autônomo só faz aquilo que lhe dá prazer. As forças não deixam de atingi-lo, contudo o atingem como ele quer. Portanto, falamos de uma autonomia como uma instância da decisão.

As narrações dos professores de Matemática nesta pesquisa apontam compreensões do que é, para eles, autonomia na escola. Discutem a utilização de materiais didáticos obrigatórios e a interferência pedagógica que isto provoca. Ainda estamos longe de uma Hermenêutica do Professor, porém já percebemos a falsa autonomia surgindo no discurso dos professores.

\section{O que vocês entendem por ter autonomia na escola?}

Fer: Quando se fala em autonomia na escola, todo mundo pensa logo nesse caderninho ${ }^{6}$.

Sempre! Porque ninguém gostaria de usar, mas tem que usar. E os alunos também cobram, porque eles ganham o caderno e querem saber se vamos usar na aula. Então, quando a diretora vai na sala e pergunta se eu estou usando os caderninhos, eu vou falar que eu estou! Mas eu não estou usando assim exatamente daquela maneira que deveria ser.

O que acontece se o professor não usar?

Fer: Dizem que é contra a lei, que tem que usar! Também falam que se o aluno reprova e entra com recurso, e fica comprovado que você não usou os cadernos, o aluno ganha o recurso, sendo automaticamente promovido naquele ano. Isso porque o professor está errado, pois não usou o caderninho. Eu penso que o professor devia falar assim: "Acho melhor usar o livro didático e as anotações que eu considero pertinentes". O professor devia ter a liberdade dessa escolha, mas não tem! A gente tem escolha para dispor a sala do jeito que a gente preferir, por exemplo, podemos formar um círculo, podemos sentar no chão, podemos fazer uma aula lá fora... esse tipo de autonomia a gente tem.... na verdade, é uma falsa autonomia...é só até certo ponto, sabe.

Isto te incomoda?

\footnotetext{
${ }^{6}$ Os 'caderninhos' foram implantados no ano de 2009 em todas as escolas da rede pública estadual de São Paulo com o objetivo de unificar o currículo pedagógico. SECRETARIA DA EDUCAÇÃO DO ESTADO DE SÃO PAULO. Caderno do Professor. [c2013]. Disponível em: 〈http://www.educacao.sp.gov.br/caderno-professor〉. Acesso em: 02 de jun. 2015.
} 
Fer: Ah, um pouco, porque eu acho que faz parte do nosso trabalho decidir como vamos trabalhar! Com a minha formação e experiência eu sei o que é melhor para a sala de aula. O ano passado uma professora que trabalhava com os sextos anos, isso numa outra escola ... contou que os alunos do quinto ano chegaram "zerados". Eles não sabiam resolver nem as quatro operações básicas. E ela contou que não usou a apostila, não tinha como! .... e realmente o caderninho é difícil para eles, a maioria das atividades tem que ser dirigida... nas minhas salas são poucos, uns dois ou três em cada sala, que são "super zerado" (Conversa da pesquisadora com os professores na ATPC de Matemática. SILVA, 2014, p. 144- 146).

Fer: A gente usa o caderninho, mas é como a diretora fala: "Tem gente que usa realmente e tem gente que finge que usa".

Altair: Eu não trabalho com o caderninho. Eu finjo que eu trabalho, eu digo, ah eu tô trabalhando isso aqui. Na verdade, eu enrolo a coordenação. Eu finjo mesmo.

Lucinéia: Eu também não gosto e não uso, mas vocês sabem, tem a cobrança da coordenação e direção. Esse ano teve até a visita de uma mulher com uma câmera na mão ... para tirar foto da forma que o professor estava usando o caderninho do aluno...Eles fazem toda uma propaganda que o caderno parece até legal. Mas, a gente é obrigada a ter aquele caderninho em cima da mesa. Isso é horrivel.... a mulher da diretoria simplesmente entrou na minha sala e viu que eu não estava usando o caderninho, ai ela falou para eu usar... uso um livro que eu gosto porque tem atividades interessantes, era o que eu estava usando... eu não ia usar o caderninho só porque ela vinha na escola! Mas eu queria fazer isso sem precisar ficar contra as regras (Conversa da pesquisadora com os professores na ATPC de Matemática. SILVA, 2014, p. 146 - 148).

Como o professor de Matemática pode lidar com as subjetivações (poderes) instituídas na escola? Um caminho para essa resposta é tratado por Foucault (2010) que mostra, através das práticas e dos exercícios do cuidado de si e da autonomia na Grécia antiga, que não há outra forma de resistência ao poder senão na relação de si para consigo. Ou seja, Foucault nos mostra que há um poder que o sujeito pode manipular: o poder sobre ele.

A autonomia diz respeito à imanência do sujeito. “... apenas se se conceber o plano de imanência será possível conceber uma vida que não se prenda a uma subjetividade ou a uma objetividade. A vida, por excelência" (LEVY, 2011, p. 105). Assim, a invenção do ser professor autônomo nasce do sujeito que resiste às forças do fora criando a dobra do fora.

O cuidado de si é entendido como a dobra do eu formada no sujeito. Dobra que luta com o fora. Cada vez que o sujeito inverte uma força, ele cria a dobra (dobra uma força). "[...] o fora ou, o plano de imanência, nos coloca diante do mundo, e não em outro mundo" (LEVY, 2011, p. 104). O Eu professor de Matemática autônomo surge nestas lutas, resistências, controle das subjetivações que agem sobre ele.

Nesse sentido a experiência do fora é um processo de resistência, uma luta da língua menor contra seu modo maior, das tribos contra o Estado, das minorias contra a maioria. Resistir é perceber que a transformação se faz necessária, que o intolerável está presente e que, portanto, é preciso construir novas possibilidades de vida (LEVY, 2011, p. 100).

Visando esses combates e essas lutas inerentes às relações de poder vislumbramos o professor autônomo. É sabido, diante de nossas práticas e pesquisas em escolas públicas do 
Estado de São Paulo, que encontramos uma estrutura escolar verticalizada, formada por uma ordem (hierarquia) de poder de cima para baixo (Ministério da Educação, Secretaria da Educação, Diretoria Regional, diretor da escola, coordenador pedagógico, coordenador de área, professor, alunos, família) e horizontalizada (GALLO, 2008b). Nessa estrutura também encontramos certas imposições como o uso dos 'caderninhos', o uso de livros didáticos, a sequência dos conteúdos, a preparação para o Sistema de Avaliação de Rendimento Escolar do Estado de São Paulo (SARESP), o cumprimento do currículo escolar, entre outras. Consequentemente, eis a importância do professor autônomo que, "constituído da prática do cuidado de si, consegue reverter, dobrar, controlar e limitar esses poderes, essas linhas de forças" (BOVO, 2011, p. 178, destaques nossos).

Lucinéia: Quando penso na minha autonomia enquanto professora de Matemática a ideia que me vem na cabeça é uma porta fechada! Eu não tenho autonomia! Eu queria uma porta aberta, um caminho que me leve para a liberdade. Você quer saber por que uma porta fechada?... o problema está em quem faz as leis, quem pensa na Educação desse Estado e depois despeja para os professores que obedecem ou fingem que obedecem! Quer exemplo? Pensa, como trabalhar da forma que pedem num período de 50 minutos com 40 alunos na sala de aula! Como? ... com aquele caderninho do aluno! Você tem que obedecer! É bom ter um roteiro? É! ... nã no sei trabalhar com esses cadernos... mas sou obrigada! ... trabalho duas páginas e o resto fica na mochila do aluno ... ah, então você tem autonomia professora, você não usa! Eu te respondo: É eu não uso, mas a cobrança? E a pressão? (Conversa da pesquisadora com os professores na ATPC de Matemática. SILVA, 2014, p. 18-19).

[...]. É preciso abrir-se ao possível, ao ainda não, ao impensado e ao impensável, e tudo isso é arriscado. Os métodos, as avaliações, os variados instrumentos de controle, são tentativas de conter as diferenças, barrar as singularidades, massificar, dominar. Mas felizmente a vida escapa, a vida é uma multiplicidade de linhas de fuga, e há aqueles que conseguem singularizar. O investimento numa "pedagogia do risco", numa "filosofia da diferença", vai na direção de potencializar e multiplicar essas linhas de fuga. Fazer com que as diferenças e as singularidades vazem por todos os poros (GALLO, 2008a).

Já é sabido que na maioria das escolas nota-se a determinação de regras e normas de desenvolvimento no trabalho dos professores, como, por exemplo, o uso obrigatório de apostilas e materiais didáticos, o cumprimento de determinada sequência de conteúdos, a aplicação de provas em datas pré-determinadas, elaboração das avaliações com conteúdos pré-determinados, forma de pontuação das avaliações e modo de correção pré-estabelecido, entre outras imposições determinadas pela coordenação, direção e secretaria da educação.

O contexto acima surge na prática de professores formados em universidades públicas e privadas, incluindo professores com título de especialista, mestre e doutor. Entretanto, nada ou quase nada fazemos debaixo de tantas normas e regras impostas. E o que acontece quando nada parece acontecer? Talvez o mesmo que Foucault nos fala no prólogo de "As Palavras e as Coisas": "Assim, em toda cultura, entre o uso do que poderia chamar códigos ordenadores 
e as reflexões sobre a ordem, há a experiência nua da ordem e dos seus modos de ser” (1999, p. 12). Portanto, a relevância de pensarmos em questões do tipo: Como inverter, vergar essas forças? Como se dá um sujeito autônomo?

Também vale lembrar que as instituições escolares superiores, tanto públicas quanto privadas, dentro de um sistema capitalista, estruturam-se como empresas que se interessam pelo lucro, advindo da mais valia sobre o trabalho docente. E, mais, são instituições que trabalham na formação do profissional (do engenheiro, do professor, etc.), mas não da pessoa. Paralelamente, como toda empresa, as instituições de ensino possuem regras básicas de funcionamento, e neste caso, o professor, antes mesmo de se imaginar numa sala de aula, deve respeitar regras correspondentes a uma cadeia hierárquica como, por exemplo, as regras impostas pelas Leis de Diretrizes e Bases da Educação (9394/96), pela direção da escola e pela coordenação de cursos. Deleuze e Parnet (1998), comentando a obra de Foucault, destaca que para este, a autonomia do sujeito se encaminha para um pensar a vida como uma obra de arte e para isto a ética de si e a coragem da verdade buscam juntas um sujeito verdadeiro, coeso internamente, em que as subjetivações exteriores só o atravessam na exata medida em que o sujeito permite.

O que Foucault encontra no pensamento antigo é a ideia de inscrever uma ordem na própria vida, mas uma ordem imanente, que não seja sustentada por valores transcendentais ou condicionada do exterior por normas sociais: 'A moral dos gregos está centrada em um problema de escolha pessoal e de uma estética da existência. A ideia do bíos como material para uma obra de arte estética é algo que me fascina. Também a ideia de que a moral pode ser uma estrutura muito forte de existência sem estar ligada a um sistema autoritário, nem jurídico em si, nem a uma estrutura de disciplina'. A elaboração ética de si é antes o seguinte: fazer da própria existência, desse material essencialmente mortal, o lugar de construção de uma ordem que se mantém por sua coerência interna (GROS, 2010, p. 479-480).

As práticas de si permitem ao sujeito encontrar as regras e normas que ele permite que o subjetivem. Ou melhor, as práticas de si ao serem constituídas como práticas com os outros são destituídas de qualquer significado egoísta do sujeito. Ao contrário, elas buscam a partir dos pensamentos socráticos um cuidado de si que é feito com o outro. Em um texto de Foucault (1992), A escrita de si, publicado em “O que é um autor?", é narrada a correspondência entre Sêneca e Lucílio que cuidam um do outro através da prática epistolar. O cuidar de si é feito com o outro que alerta de descuidos e ao qual alertamos de práticas saudáveis. A correspondência facilita o exame da vida cotidiana e de nossas práticas diárias como a alimentação, os esportes e as atividades de leitura e estudos. Permite ainda o exame de consciência compartilhado.

A prática de si não aparece mais [...] como um complemento, uma peça indispensável ou substitutiva da pedagogia - ela vale para o desenrolar de toda a vida, identifica-se e incorpora-se com a própria arte de viver. Além disso, a 
desvinculação da prática de si em relação à pedagogia traz outra consequência: a prática de si, não se inscreve mais na relação dialética e amorosa entre o mestre e o discípulo, mas integra-se, mistura-se, entrelaça-se com toda uma rede de relações sociais diversas (MARTINS, 2007, p. 79).

E você sempre respeita as decisões da direção e coordenação?

Lucinéia: Ah, sim! Porque se eu não fizer como eles querem, eu nunca mais serei ouvida.

Ouvida por quem?

Lucinéia: Pela direção! Se você respeita eles, e diz sim para tudo, você é respeitado! Se você diz não, ou você não concorda e tenta fazer uma coisa diferente, você não é ouvido. Aí o que acontece, por exemplo, se eu vou procurar alguém para expor: "Ah, eu tô precisando disso, quero fazer tal projeto", ninguém me ouve, ou seja, suas ideias não são aceitas.

E como você se sente nessa situação?

Lucinéia: Impotente. A escola hoje é impotente! Os alunos que terminam o Ensino Médio, muitos não sabem que rumo vão tomar. Estão perdidos! A escola está uma bagunça! Se eu soubesse que era assim, eu nem teria entrado nesse meio. Eu achei que eu poderia ter voz, porque na graduação eles colocam esperança na gente, então eu pensei que eu fosse fazer a diferença enquanto professora. Mas a gente não faz! (Conversa da pesquisadora com os professores na ATPC de Matemática. SILVA, 2014, p. 23-24).

\section{Engendramentos outros}

Quais as possibilidades de ser professor? Os professores conseguem sair da manada ${ }^{7}$, do rebanho $^{8}$ ? Eles tomam decisões autônomas, ou seja, decididas por ele? Ou trabalham no piloto automático do senso comum? Os professores têm controle das suas práticas e táticas escolares? Ou são controlados pelos poderes e saberes vigentes? Há resistências nas escolas? Sempre seremos manipulados pelo poder? Ou podemos traçar caminhos outros na educação, caminhos para resistência e lutas.

De acordo com Foucault devemos optar pelo múltiplo, pelos fluxos ao invés das unidades, pela diferença ao invés da uniformidade, preferir os agenciamentos móveis aos sistemas. "O que é preciso é desindividualizar pela multiplicação e pelo deslocamento, pelo agenciamento de combinações diferentes. O grupo não deve ser o elo orgânico que une indivíduos hierarquizados, mas um constante gerador de desindividualização" (FOUCAULT, 1977, p.3, grifos do autor).

Entendemos como necessário apontar formas outras de pensar a educação, formas que contrariem ou sejam rotas de fuga às ideias de feixes perpendiculares - relações de poder verticais à escola e ao professor de Matemática - e, menos ainda, de feixes horizontais composto pelas micro redes de poder constantes na vida cotidiana das escolas -, e sim

\footnotetext{
${ }^{7}$ NIETZSCHE, F. W. (2011)

${ }^{8}$ NIETZSCHE, F. W. (2011)
} 
pensamos na possibilidade de feixes transversais ${ }^{9}$, como os encontros que desenvolvemos com os professores de Matemática, local de engendramento de rotas de fuga, de possibilidade da experiência do fora.

A experiência do fora nos coloca diante do real, mas não para continuarmos seguindo seus pressupostos, repetindo o que nos afirma o senso comum. Se o vínculo do homem com o mundo é aqui restabelecido, é antes para que se possa resistir, para que se possa transformar o que já está dado, o que não pode continuar como tal (LEVY, 2011, p. 101).

Lucinéia: $O$ dia a dia do professor de Matemática? ... pensa em algo bagunçado, bolinha de papel voando na sala, todos querendo falar ao mesmo tempo. Muitas vezes, quando eu consigo falar os alunos dão as costas... eu grito! Explico uma matéria ...enquanto uns abaixam a cabeça prá tentar resolver, o restante vira pros lados, conversa: "Cê entendeu? "... "não! ”... "Que coisa mais chata isso, nem quero fazer". E por mais que você tente fazer coisas diferentes...eles querem o Facebook ou jogos sem conteúdo matemático... só se eu mudasse o nome da Matemática ..., mas até isso eu já tentei fazer ... inventei umas histórias lá...não deu certo. O que eu estou fazendo aqui? (Conversa da pesquisadora com os professores na ATPC de Matemática. SILVA, 2014, p.20).

A pesquisa de Bovo (2011) a respeito da cultura-escolar-prática-pedagógica-doprofessor-de-matemática contribui significativamente com os questionamentos aqui apontados, uma vez que seu trabalho destaca as dificuldades dos professores em percorrer caminhos diferentes daqueles impostos pela gestão escolar. Seus estudos trazem indícios do porquê algumas práticas prevalecem em detrimento às outras, visto que as condições do trabalho do professor são precárias, as relações de poder estão entrelaçadas à cultura escolar e existe um exagerado controle sobre o currículo.

O espaço da escola é um espaço estriado, cheio de leis, regras, hierarquias, inspeções. Os ocupantes desse espaço têm um único caminho a seguir - o mesmo que de uma árvore. Não há multiplicidades, desejos, aberturas. Com suas normas de conduta, com seus currículos, com suas disciplinas, com seus livros didáticos, apostilas e hierarquias a escola promove discursos, e é toda organizada de modo a produzir verdades (BOVO et al., 2011, p. 34-35, grifo do autor).

\section{$\mathbf{P A}^{10}$ ?}

Patrícia: Professora assistente. A função do PA é auxiliar o professor na sala de aula.

Fer: $O$ PA também precisa preencher uma ficha, fazer um relatório de como foi a aula do professor. Depois o professor também tem que preencher um relatório do trabalho do PA na aula dele e escrever se houve melhora dos alunos com a parceria do PA.

Altair: O professor assina um termo de aceite do PA na sua sala de aula.

Fer: Apesar de assinar esse termo, eu não entendi que a gente podia optar pelo PA.

Conversaram sobre isso com a direção?

\footnotetext{
${ }^{9}$ Podemos, assim, tomar a noção de transversalidade e aplicá-la à imagem rizomática do saber: ela seria a matriz da mobilidade por entre os liames do rizoma, abandonando os verticalismos e horizontalismos que seriam insuficientes para uma abrangência de visão de todo o "horizonte de eventos" possibilitado por um rizoma. (GALLO, 2008b, p. 79)

${ }^{10}$ Sigla utilizada para se referir ao Professor Auxiliar. SECRETARIA DA EDUCAÇÃO DO ESTADO DE SÃO PAULO. Escolas estaduais terão professor-auxiliar e novos modelos de recuperação. [2012]. Disponível em: <http://www.educacao.sp.gov.br/noticias/escolas-estaduais-terao-professor-auxiliar-e-novos-modelos-derecuperacao >. Acessado em: 30 de out 2015.
} 
Fer: Não, porque, na verdade, acho que todo mundo gostou de ter outro professor ajudando na sala de aula.

James: Mais relatórios na escola! Um vigiando o outro. Para mim os PAs têm outra finalidade dentro das salas de aula. Vejam bem, no ano passado os gestores começaram a assistir às aulas dos professores e, ainda, tinham que entregar um relatório dessas aulas. Parece que isso aconteceu em todas as escolas públicas do Estado de São Paulo. Então, para mim os PAs são uma estratégia do Estado para livrar os gestores do trabalho desses relatórios.

E como vocês preenchem esses relatórios? O que escrevem?

Fer: Eu me baseio no caderninho dos alunos, porque lá já tem o objetivo, as habilidades e tudo mais daquela aula, daquele conceito. Mas, acaba que os relatórios não mostram as reais dificuldades da sala de aula.

Você não escreve o que realmente acontece na sala de aula? Suas dificuldades, a indisciplina, os problemas? Não é até contraditório escrever que os alunos trabalharam tais e tais habilidades

Patrícia: A maioria dos alunos não sabe nem divisão com um algarismo.

Altair: Em toda sala tem uns 10 alunos que não querem nada com nada! ... Eles ficavam correndo, jogando bolinha... A culpa é de quem? (Conversa da pesquisadora com os professores na ATPC de Matemática. SILVA, 2014, p. 25-27).

É possível enfrentar esse sistema arbóreo ${ }^{11}$ ? É possível criar novos territórios com rotas de fuga? Há possibilidades de desterritorialização na escola? É possível uma escola rizomática, que agencia seus componentes? Entende-se que precisamos de novos tipos de relações na escola, da possibilidade de praticar resistências, lutas, vidas outras, romper com as linhas imaginárias do poder. "Que acontecimentos podemos suscitar, que linhas de fuga aos mecanismos de controle podemos pôr em marcha?" (GALLO, 2008b, p. 90).

\begin{abstract}
"O que é um território? Nada mais do que um conjunto de códigos: um conjunto de códigos num território. $\mathrm{O}$ que implica em dizer que, quebrado um território, ocorre uma desterritorialização; mas também uma descodificação. [...]. Por exemplo, século XVIII, nascimento do capitalismo, cercamento da terra - desterritorialização; fim da família patriarcal - descodificação. [...] E todos que desterritorializam e descodificam podem ser chamados de MÁQUINAS DE GUERRA. [...] a desterritorialização ocorre na TERRA. Então, apareceram dois conceitos: TERRITÓRIO e TERRA. A terra não é um conceito enlouquecido, não. A terra é um clamor do Nietzsche. "Chega de filosofia do céu, vamos fazer a filosofia da terra". [...] Nietzsche está chamando a terra, exatamente, de um "território" móvel. A palavra "território" foi mal aplicada: ele é móvel, não tem códigos. Vocês podem usar também no nome território também o nome extrato. [...] o homem dentro de um território ou dentro de um extrato tem um conjunto de códigos que organiza a sua vida. Então, eu vou utilizar desterritorialização como sendo LINHA DE FUGA. Então, esse conceito aí - linha de fuga — não está dentro de um território, está fora do território. A linha de fuga é um conceito propriamente kafkaniano. A obra de Kafka é exatamente isso: a produção das linhas de fuga dos territórios, dos extratos, dos deveres, das leis, da moral, da ciência, dos mitos, etc. (CENTRO DE ESTUDOS CLAUDIO ULPIANO, 2010, grifos do autor)
\end{abstract}

Buscando a possibilidade de resistências, lutas dos professores diante das dificuldades e imposições escolares, entendemos que é "preciso mudar o cidadão para mudar a escola. Criar espaços na sociedade para que as pessoas busquem formas outras de subjetivação" (BOVO, 2011, p. 179).

${ }^{11}$ DELEUZE; GUATTARI, (1996) 
O estudo e principalmente a prática do cuidado de si e da autonomia pode influenciar e alimentar ações atuais da educação geral, em particular, da Educação Matemática, inclusive, no que se refere como possibilidade do sujeito da educação assumir o controle das subjetivações que agem sobre ele. Entretanto, “Como podemos inserir o professor - enquanto profissional - em uma prática do cuidado de si se o cidadão não está inserido nesta prática?” (BOVO, 2011, p.179, grifos do autor).

Existem tentativas de propor mudanças nas práticas pedagógicas escolares entre elas podemos citar: os Parâmetros Curriculares Nacional - PCN’s, a Proposta Curricular do Estado de São Paulo, o Sistema de Avaliação de Rendimento Escolar do Estado de São Paulo SARESP, entre outras. No que se refere ao ensino-aprendizagem de Matemática podemos citar algumas tendências em Educação Matemática, tais como: Etnomatemática, Modelagem, Resolução de Problemas, História da Matemática, Tecnologias da Informação e Comunicação (TIC).

As últimas tentativas de mudança, em geral, acontecem por meio de cursos de formação continuada oferecidos pelas universidades através de projetos de pesquisa, extensão e parcerias com governos municipais e estaduais. Ou seja, são ações que não partem dos professores que se encontram lecionando nas escolas públicas, mas, partem de instâncias governamentais e educacionais superiores. Assim, apesar desses cursos oferecerem algumas contribuições, eles não garantem mudanças nas práticas dos professores, uma vez que estes ao retornarem para a escola encontram "situações conflitantes causadas pelo confronto entre a realidade vivenciada no curso e a organização da escola" (OLIVEIRA, 2003, p.120).

Entre outras ações que buscam contribuir para o desenvolvimento profissional dos professores, citamos o trabalho colaborativo (CANCIAN, 2001; FIORENTINI, 2006) realizado entre pesquisadores, professores e futuros professores, que têm como objetivo trocar experiências, conhecer novas metodologias de ensino, refletir sobre sua prática de sala de aula, estudar. Contudo, segundo Cancian (2001), o trabalho colaborativo tem algumas limitações, visto que, alguns professores, mesmo que refletindo coletivamente, não demonstram mudanças na forma de pensar e agir.

Percebemos que muitas práticas colaborativas se limitam a conversas e reflexões só sobre a melhora da prática metodológica do professor, não atingindo uma reflexão sobre o sujeito existente em cada professor que reflete a sua prática. Ou seja, trocam experiências sobre a profissão e não sobre os sujeitos e suas práticas, portanto não caminham na direção do cuidado de si e da autonomia. 
Apontamos, neste artigo, que é importante o professor pensar suas práticas e táticas escolares segundo o que ele entende como necessário e essencial para ele, mesmo que isso vá contra os discursos salvos da educação. Pensar essas questões de acordo com a verdade dele, que ele produz. De acordo com Foucault, a verdade do sujeito está atrelada a dois princípios: o conhecimento de si e o cuidado de si. Ou seja, a necessidade do professor se cuidar está implicada na ideia dele se conhecer, de tomar atitudes e ações condizentes com a verdade dele.

Segundo o modo proposto na cultura Grega do cuidado de si - o sujeito só é subjetivado a ele mesmo -, a constituição de si como sujeito é função de uma tentativa indefinida de conhecimento de si, ou seja, a importância de conhecer quem sou verdadeiramente e não o que creio ser; o que faço, os atos que realizo só têm valor enquanto me ajudam a melhor me conhecer (FOUCAULT, 2010).

Consequentemente o caminho da autonomia é a prática do cuidado de si que nos leva à coragem da verdade. Posto que a autonomia de que falamos é algo de conquista do indivíduo; ela não é cedida ao sujeito, mas é uma força que vem de dentro dele, diferentemente daquela autonomia decidida em instâncias hierárquicas superiores. A autonomia de Foucault vem de dentro para fora.

\footnotetext{
A pergunta que fica é: Como uma rede escolar ou uma escola pode "incentivar" a prática do cuidado de si entre os professores já que esta prática é fundamental? É aí que se encontra o grande nó, pois o cuidado de si não é algo exterior ao sujeito. A autonomia não é cedida a ele, mas é uma força que vem de dentro dele! (BOVO, 2011, p. 178, grifos do autor)
}

Ao longo de nossa pesquisa e, particularmente, das cartografias dos professores, as questões do ser/existir como sujeito autônomo e do fazer/prática escolar vão elucidando pontos interessantes da autonomia e de como os professores a entendem no seu dia a dia. Apontam no sentido ora de fragilidade ante o sistema ora de rebeldia contra as regras impostas pelo aparelho escolar. Isto posto, caso a Educação Matemática aponte caminhos para eliminar regras e normas dentro das escolas existem potências na busca do cuidado de si.

Qual é a 'autonomia' de vocês enquanto professor de Matemática? Quem gostaria de representar essa ideia num desenho?

James: Olha, é meio complicada essa questão. Eu nem sei como desenhar isso. Então, isso é mesmo uma representação, porque eu não sinto que tenho autonomia. 


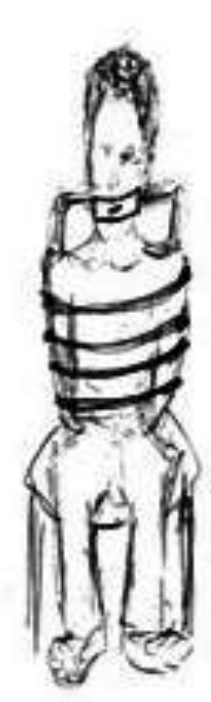

Figura 1: Desenho do professor James sobre a autonomia do professor de Matemática (SILVA, 2014, p.176).

James: Eu me sinto preso. Não consigo ver autonomia na maneira que a escola funciona ... eu me sinto vigiado no que eu estou fazendo com meus alunos... me sinto podado... simplesmente não posso trabalhar do jeito que eu gostaria... da maneira que eu penso.

O que te impede?

James: Simplesmente amarrado ... não sei o que é que me impede, mas sei que não é

possível... a respeito da autonomia do professor...estava desenvolvendo um projeto com o observatório da USP ... pegava os alunos e levava na quadra para realizar os experimentos... Depois íamos para a sala de informática descrever os resultados, tudo isso fora do meu horário de aula... não houve nenhum tipo de suporte da escola ...você pode fazer qualquer coisa que você quiser, desde que dê certo...caso contrário é: "Foi você quem quis fazer! Não temos nada com isso!'”... sou do tipo que não gosta de se submeter a regras...forças invisíveis que aparecem algumas vezes em forma de regras...ou a ideia de que é natural ... é normal isso tudo em uma escola... no desenho, a ideia é que eu estou recusando determinadas condições, a ideia é fugir, alguma fuga... por isso eu associo mais esse meu comportamento a uma recusa, a uma indisciplina (Conversa da pesquisadora com os professores na ATPC de Matemática. SILVA, 2014, 175-177).

Éder: Quanto à autonomia do professor na sala de aula...devemos ter uma diretriz, que neste caso é a proposta curricular do Estado de São Paulo... entendo que tenho autonomia na sala de aula, pois todas as coisas que me propus a fazer eu nunca fui impedido... sempre consegui usar o data show nas minhas aulas ... eu consigo trabalhar muito bem... Eu nunca senti que eu não podia fazer algo que eu quisesse ... Minha ideia de autonomia é quando o próprio patrão do sujeito é ele mesmo...o autônomo sabe o que ele tem que fazer... e ele procura os meios em que ele possa chegar nesses objetivos.... Essa autonomia me dá assim uma sensação de liberdade.

Fer: ...o professor não tem autonomia, pois devia ter a autonomia de falar assim: eu acho melhor usar o livro didático e anotações que eu considero pertinentes... o professor não tem essa liberdade na escola...A gente tem autonomia de dispor a sala do jeito que quisermos...na verdade é uma falsa autonomia (Conversa da pesquisadora com os professores na ATPC de Matemática. SILVA, 2014, p. 178).

A narrativa do professor James é singular e, principalmente, marcada por fortes traços de luta contra o instituído. Ele inicialmente se considera amarrado e impossibilitado de reagir contra as regras, forças invisíveis do fora, naturalidades e normalidades. Busca por uma linha de fuga ou rota de fuga. Mas a escola não é um rizoma. Não há espaço para o "patrão de si mesmo". Vai além e sua fala ressoa "na verdade é uma falsa autonomia". Porém a fuga para o 
professor James é distinta da fuga dos professores Altair, Lucinéia e Pati. Estes optam por uma fuga sem potência do novo "o dia a dia desta escola é uma cruz" e continua "Eu tô fugindo". Para Lucinéia a "autonomia é uma porta fechada" e para Pati é uma questão de obediência. A pergunta que aqui se insere é: Há possibilidade de resistência no território escolar? Anular as potências de quem adentra os muros escolares interessa a quem? Onde a vida se esconde na escola?

Altair: Eu não tenho autonomia, se eu tivesse eu teria todo o direito de usar o material didático que eu quisesse, e não sofreria essa imposição que a secretaria da educação faz. Como ter autonomia se eu me sinto preso? Ou seja, eu tô sempre querendo fugir. É isso que eu sinto.

Fugir do quê? Do que lhe é imposto?

Altair: É! Fugindo, fugindo do que é posto de cima para baixo. Vou colocar aqui da Secretaria da Educação.

Mas você não usa a apostila...

Altair: Eu sei! Não uso, mas preciso fingir que uso. Eu tô fugindo. Eu consigo isso porque estou dentro da sala de aula e mesmo assim existe essa pressão. Até dos alunos! ...o dia a dia dessa escola é uma cruz. Sou obrigado a engolir os compromissos escolares. É só compromisso que eu preciso cumprir por causa do meu aluguel, cachorro, roupa.

Lucinéia: Quando penso em autonomia imagino uma porta fechada! Eu não tenho autonomia...temos certa limitação para trabalhar do jeito que a gente quer, que a gente gostaria...o problema está em quem faz as leis, quem organiza tudo e entrega pra nós e a gente obedece, né! (Conversa da pesquisadora com os professores na ATPC de Matemática. SILVA, 2014, p. 180-181).

Pati, como você entende que é um professor autônomo?

Pati: Que ele consegue controlar a sala? É isso? E o que o professor diz é levado em consideração? Preciso de um dicionário para ver o que é autonomia. Para mim a pessoa autônoma é respeitada... ela se impõe... consegue ser ouvida. Eles me veem como igual! Um professor que tem autonomia, vai conseguir se impor se o aluno xingar ele... é o tipo de professor que promete e cumpre. Porque tem professor que fala e fala ... e não faz nada, então para que ouvir esse professor? (Conversa da pesquisadora com os professores na ATPC de Matemática. SILVA, 2014, p. 181-182).

Neste jogo de espelhos um tema e uma questão surge nas narrações: a formação do professor de Matemática. Quem forma o professor de Matemática? Aquele que fez Licenciatura em Matemática seria óbvio responder. Nas estrias do território escola existem possibilidades outras para isto. Durante a pesquisa encontramos dando aula de Matemática um engenheiro e uma professora formada em Química. A proximidade da engenharia com a Matemática é um dos mitos mais antigos de nossas escolas, ou seja, algo que recobre a eterna falta de professores de Matemática. Mas a Química é mais distante e a professora Cris faz um relato das subjetivações a que está submetida por ausência de conteúdo matemático e, quase pergunta, como ensinar se não sei Matemática?

Cris:... sinto que sou uma pessoa totalmente agitada, incapaz na sala, e ainda tem o desrespeito dos alunos comigo ... é sempre assim, não importa a sala ... isso tudo também aconteceu nos anos anteriores... minha rotina na escola é como se fosse um dia triste. Um dia bobo, um dia pálido, e uma pessoa triste e preocupada com tudo que pode vir acontecer durante o dia. Esse desenho é uma representação de como me sinto como professora de Matemática. 


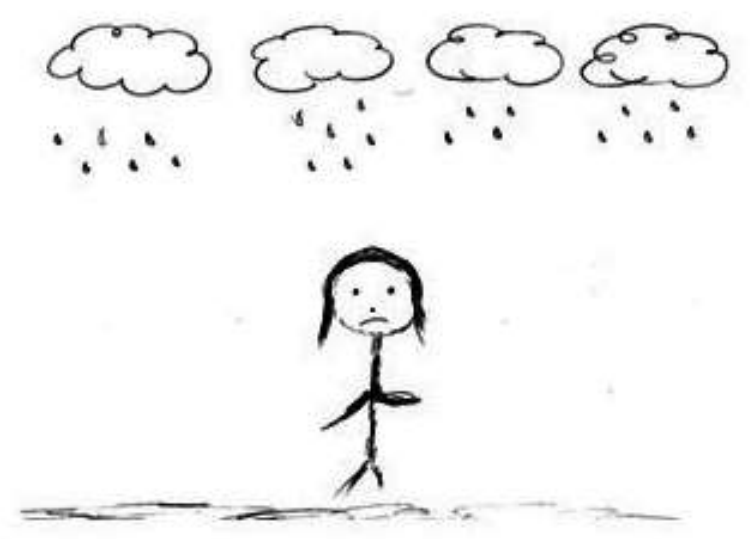

Figura 2: O dia a dia do professor de Matemática para a Cris (SILVA, 2014, p 94).

Mas você está preocupada com o conteúdo ou com o as atitudes dos alunos?

Cris: Com as atitudes dos alunos. Como vão aceitar o conhecimento. Não é fácil ... quando eu vim lecionar Química aqui no primeiro bimestre, o segundo e terceiros anos não me aceitaram ... aos poucos eu os fui conquistando ... dentro da Matemática eu ainda não consegui atingir esse ponto. Eu preciso tentar relaxar, ficar calma ... eu já vou agitada para o sétimo ano porque eu sei que vou ter que gritar ... eu não tenho esse preparo comigo.

Penso que é importante você entender onde se sente bem e onde não se sente bem. É importante você se conhecer Cristiane.

Cris: Pensando nisso, no ano que vem, eu não espero pegar aula de Matemática. Sabe, já teve vezes de eu chegar em casa chorando, descontente mesmo (Conversa da pesquisadora com os professores na ATPC de Matemática. SILVA, 2014, p.94-96).

Cris: ... devido a minha formação em Química... eu não tenho autonomia enquanto professora de Matemática ... tenho deficiência no conteúdo... Ter autonomia para mim seria estar feliz com meu trabalho ... conseguir a disciplina da sala, ter total domínio do conteúdo e conseguir transmitir aos alunos.

Você acha que esse processo da autonomia do professor tem que partir da formação universitária, de cursos ou do próprio professor? (SILVA, 2014, p.178)

Cris: Tem que partir de mim. É algo que vai partir de mim. Eu ainda não consegui encontrar o caminho (Conversa da pesquisadora com os professores na ATPC de Matemática. Silva, 2014, p.179).

\section{Potências do cuidado de si: o exercício da parrhesía}

Os encontros com os professores de Matemáticas se tornaram um espaço de permanente embate que caminharam no sentido de um estar consigo. Buscando a possibilidade de escapar das capturas das individualidades, construímos nosso espaço, nosso território, nosso código para dar sentido à questão luta/resistência. Luta do sujeito contra a subjetivação indesejada, resistência às forças segundo nossas verdades.

Ressaltamos que tal resistência, luta, depende de uma atitude muito simples, porém pouco praticada na escola: dizer a verdade. A verdade está atrelada à ética do sujeito entendida como "fala franca" - parrhesía. “[...] A parrhesía, traduzida em geral por 
"franqueza", é uma regra do jogo, um princípio de comportamento verbal que devemos ter para com o outro na prática da direção de consciência” (FOUCAULT, 2010, p. 148).

A sala de aula de Matemática é um ambiente parrhesiástico? O professor de Matemática governa a si próprio para governar seus alunos? Foucault mostra-nos que o desenvolvimento da prática de si, na Grécia antiga, possibilita certa relação social entre indivíduos que produz uma nova ética na relação com o Outro. "E é essa nova ética da relação verbal com o outro que está designada na noção fundamental de parrhesía" (FOUCAULT, 2010, p.148). Compreendemos que se os professores forem éticos em relação a si existe uma grande possibilidade que surjam mudanças nas práticas e táticas docentes o que provocaria mudanças no espaço escolar. Novas potências de vida habitando o espaço escolar. Vida parrhesiástica. Novos fluxos, novos agenciamentos, mundos outros. O professor que é ético com ele mesmo, é ético com seus alunos, com a matéria que leciona, com seus colegas de trabalho, com a escola. Quando o professor governa a vida dele, ele governa a sua sala de aula, sua participação na ATPC e governa outros compromissos da escola. Caso a escola fosse um corpo sem órgãos ${ }^{12}$ e, por isso mesmo, o professor cuidaria da escola, a escola dele cuidaria.

Se ao ocupar-se comigo, ao praticar a catártica no sentido neoplatônico, faço como assim desejo, o bem à cidade que eu governo [...] em troca, essa prosperidade de todos, essa salvação da cidade, essa vitória que lhes asseguro, será de meu proveito, na medida em que faço parte da própria comunidade da cidade. Na salvação da cidade o cuidado de si encontra, pois, sua recompensa e garantia. Salva-se a si mesmo na medida em que a cidade se salva e na medida em que, ocupando-se consigo mesmo, permitiu-se à cidade que se salve (FOUCAULT, 2010, p. 159).

A fala da professora Cris "Tem que partir de mim. É algo que vai partir de mim. Eu ainda não consegui encontrar o caminho" (SILVA, 2014, p.179), indica a possibilidade de que a professora compreendeu que depende dela as mudanças que ela deseja fazer, que ela pode aceitar ou não o que lhe é imposto, que ela pode sim resistir ao que ela não deseja. Porém, para isso ela precisa conhecer o que lhe faz bem e o que não lhe faz bem. Essa fala, bem como as falas e ações dos professores e da escola pesquisada anunciam movimentos de resistências e buscas constantes de linhas de fuga. Denunciam uma estrutura da qual todos querem fugir. Denuncia a escola como instituição. Anuncia práticas do cuidado de si.

Estas questões entre outras tantas apontadas ao longo desse texto indicam a necessidade de um movimento molecular nas escolas, da necessidade de estimularmos os movimentos do "eu saber lidar consigo próprio", contrário aos movimentos molares

\footnotetext{
${ }^{12}$ DELEUZE e GUATARRI (1996)
} 
(sindicatos, partidos, etc.) ou ainda aos movimentos de manada. Manada que não pensa, não decide, que é arrastada por ideias e pelas decisões de um "pastor".

Buscamos com este estudo possibilitar caminhos outros, escolas outras, professores outros, alunos outros, pesquisadores outros. E ainda, que esses encontros e conversas possibilitem criar conceitos que deem consistências a acontecimentos na educação escolar. Conceitos que disparem um pensamento, que permitam o pensar.

A pesquisa de Silva (2014) e este artigo investem na possibilidade de os conceitos aqui apresentados produzirem acontecimentos, proporcionando novas formas de visibilidades na escola. Reconhecendo os poderes e principalmente as resistências, (entendidas como criação e produção de singulares formas de viver) que devemos estar permanentemente atentos e vigilantes. Portanto, nos preocupamos com a possibilidade de constituir novos modos de existência, novas subjetividades, possibilidade de criar espaços de liberdade no presente.

\section{Referências}

BOVO, A. A. Abrindo a caixa preta da escola: uma discussão acerca da cultura escolar e da prática pedagógica do professor de matemática. 2011. $190 \mathrm{f}$. Tese (Doutorado em Educação Matemática) - Instituto de Geociências e Ciências Exatas, Universidade Estadual Paulista, Rio Claro, 2011.

BOVO, A. A. et al. Pesquisando práticas e táticas em educação matemática. Bolema, Rio Claro, v. 25, n. 41, p. 1-41, dez. 2011.

CANCIAN, A. K. Reflexão e colaboração desencadeando mudanças - Uma Experiência de Trabalho Junto a Professores de Matemática. 2001. 165 f. Dissertação (Mestrado em Educação Matemática) - Instituto de Geociências e Ciências Exatas, Universidade Estadual Paulista, Rio Claro, 2001.

CASTRO, E. Vocabulário de Foucault - um percurso pelos seus temas, conceitos e autores. Tradução de Ingrid Muller Xavier. Belo Horizonte: Autêntica Editora, 2009. 477 p.

CENTRO DE ESTUDOS CLAUDIO ULPIANO. 2010. Aula de 31/05/1995 - Plano de imanência (território) ou a idéia de imagem do pensamento. Disponível em:

<http://claudioulpiano.org.br.s87743.gridserver.com/?p=1994>. Acesso em: 13 out. 2014.

DELEUZE, G. Foucault. 8 ed. Tradução de Claudia Sant'Anna Martins. São Paulo: Brasiliense, $2005.142 \mathrm{p}$.

DELEUZE, G; PARNET, C. Diálogos. Tradução de Eloisa Araújo Ribeiro. São Paulo: Escuta, 1998, $184 \mathrm{p}$.

DELEUZE, G; GUATTTARI, F. Mil Platôs - capitalismo e esquizofrenia. Tradução de Aurélio Guerra Neto et al. Volume. 3. Rio de Janeiro: Editora 34, 1996, 120p.

FIORENTINI, D. Grupo de Sábado: uma história de reflexão, investigação e escrita sobre a prática escolar em matemática. In FIORENTINI, D.; CRISTOVÃO, E. M. (Org.). História e investigação de/em aulas de Matemática. Campinas: Editora Alínea, 2006. 
FOUCAULT, M. Introdução à vida não-fascista. 1977. Disponível em: < www.filoesco.unb.br/foucault> Acesso em: 20 de abril de 2012.

FOUCAULT, M. O que é um autor? 3 ed. Lisboa: Passagens, 1992. 160 p.

FOUCAULT, M. As palavras e as coisas: uma arqueologia das ciências humanas. Tradução de Salma TannusMuchail. São Paulo: Martins Fontes, 1999. 541 p.

FOUCAULT, M. História da Sexualidade 3: o cuidado de si. Tradução de Maria Thereza da Costa Albuquerque. 8 ed Rio de Janeiro: Edições Graal, 2005. 246 p.

FOUCAULT, M. História da Sexualidade 1: a vontade de saber. Tradução de Maria Thereza da Costa Albuquerque e J. A. Guilhon Albuquerque. 17. ed. Rio de Janeiro: Edições Graal, 2006. 176 p.

FOUCAULT, M. História da Sexualidade 2: o uso dos prazeres. Tradução de Maria Thereza da Costa Albuquerque. 12 ed. Rio de Janeiro: Edições Graal, 2007. 232 p.

FOUCAULT, M. Vigiar e Punir: nascimento da prisão. Tradução de Raquel Ramalhete. 36 ed. Petrópolis, RJ: Vozes, 2009. 291 p.

FOUCAULT, M. A hermenêutica do sujeito. 3 ed. São Paulo: WMF Martins Fontes, 2010. 506 p.

GALLO, S. Entrevista com Sílvio Gallo. 2008a. Disponível em:

<http://www.petpsi.ufc.br/Documentos/>. Acesso em: 15 out. 2014.

GALLO, S. Deleuze e a Educação. 2. ed. Belo Horizonte: Autêntica, 2008b. 104 p.

GROS, F. Situação do curso. In: FOUCAULT, M. A hermenêutica do sujeito. 3. ed. São Paulo: WMF Martins Fontes, 2010, p.457 - 493.

KASTRUP, V; ESCÓSSIA, L. (Org.). Pistas do método da cartografia: pesquisa-intervenção e produção de subjetividade. Porto Alegre: Sulina, 2009, p. 52 - 75.

LEVY, T. S. A experiência do fora: Blanchot, Foucault e Deleuze. Rio de Janeiro: Civilização Brasileira, 2011.142 p.

MARTINS, R. M. Cuidado de si e educação matemática: perspectivas, reflexões e práticas de atores sociais (1925 - 1945). 2007. 293 f. Tese (Doutorado em Educação Matemática) - Instituto de Geociências e Ciências Exatas, Universidade Estadual Paulista, Rio Claro, 2007.

NIETZSCHE, W.F. 2011. Assim falou Zarastustra: um livro para todos e para ninguém. Tradução de Paulo César de Souza. São Paulo: Companhia das Letras, 2011.359 p.

OLIVEIRA, A. M. P. Formação continuada de professores de Matemática e suas percepções sobre as contribuições de um curso. 2003. 192 f. Dissertação (Mestrado em Educação Matemática) - Instituto de Geociências e Ciências Exatas, Universidade Estadual Paulista, Rio Claro, 2003.

ROLNIK, S. Cartografia Sentimental, Transformações contemporâneas do desejo. São Paulo: Editora Estação Liberdade, 1989. Disponível em <http://www.pucsp.br/nucleodesubjetividade/Textos/SUELY/pensarvibratil.pdf >. Acesso em: 18 fev. 2014.

SILVA, M. T et al. Mapas e cartografia em Educação Matemática. In: XI ENCONTRO NACIONAL DE EDUCAÇÃO MATEMÁTICA, 11., 2013, Curitiba. Anais do XI Encontro Nacional de Educação Matemática. Curitiba: editora, 2013.p. 1- 8.1 CD 
SILVA, M.T. A Educação Matemática e o cuidado de si: possibilidades foucaultianas. 2014. 192f. Tese (Doutorado em Educação Matemática) - Instituto de Geociências e Ciências Exatas, Universidade Estadual Paulista, Rio Claro, 2014.

SÃO PAULO. Coordenadoria de gestão da educação básica. Lei complementar n ${ }^{\circ}$ 836/1997. Disponível em: <http://www.dersv.com/legislacao.htm\#290108>. Acesso em: 19 fev. 2014.

SÃO PAULO. Secretaria de Educação. Caderno do Professor. Disponível em: <http://www.educacao.sp.gov.br/caderno-professor>. Acesso em: 2 jun. 2015.

SÃO PAULO. Secretaria da Educação. Escolas estaduais terão professor-auxiliar e novos modelos de recuperação. Disponível em: <http://www.educacao.sp.gov.br/noticias/escolas-estaduais-teraoprofessor-auxiliar-e-novos-modelos-de-recuperacao >. Acesso em: 30 out. 2015.

Submetido em Abril de 2015. Aprovado em Agosto de 2015. 